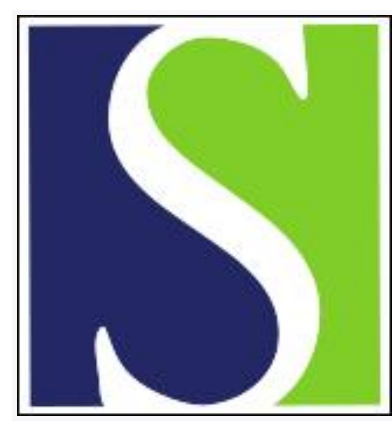

Scand J Work Environ Health 1994;20(2):146-147

https://doi.org/10.5271/sjweh.1418

Issue date: 01 Apr 1994

Pleural mesothelioma in a cigarette filter factory worker.

by Huncharek M

Affiliation: Department of Radiation Oncology, Massachusetts General Hospital, Harvard Medical School, Boston 02114.

This article in PubMed: www.ncbi.nlm.nih.gov/pubmed/8079137 


\title{
Pleural mesothelioma in a cigarette filter factory worker
}

\author{
by Michael Huncharek, MD'
}

\begin{abstract}
HUNCHAREK M. Pleural mesothelioma in a cigarette filter factory worker. Scand $J$ Work Environ Health 1994;20:146-7. The incidence of pleural mesothelioma is increasing. Over the past two decades many new occupational and nonoccupational risk groups have been identified. This paper reports a case of pleural mesothelioma in an office worker employed in a cigarette filter factory. Both secondary occupational and domestic asbestos exposure may have occurred. Only one prior report describes the potential asbestos health risks of this occupational group.
\end{abstract}

KEY TERMS - asbestos, crocidolite, mesothelioma.

Pleural mesothelioma is a relatively uncommon tumor, although its incidence is increasing $(1,2)$. The etiologic link between asbestos and mesothelioma is well established $(3,4)$, many new occupational and nonoccupational risk groups having been identified over the last decade (5). In 1989, Talcott et al (6) reported the mortality and morbidity experience of a cohort of cigarette filter workers (33 men) exposed to crocidolite asbestos (6). A marked excess in mortality and morbidity from asbestos-related diseases was described, including lung cancer, mesothelioma, and asbestosis. This communication outlines a case of pleural mesothelioma which occurred in an office worker employed in the same cigarette manufacturing plant as described by Talcott et al in 1989. This patient was not, at any time, involved in the manufacturing process and had no other known source of asbestos exposure, although domestic exposure may have occurred.

\section{Case report}

The patient was a 53-year-old white female with a 90 pack-year smoking history who was well until four months prior to presentation. At that time she developed left-sided pleuritic chest pain initially treated with nonsteroidal antiinflammatory medication with complete resolution of her symptoms. Thereafter, the patient noted a gradual onset of dyspnea on exertion without chest pain or other symptoms. A chest radiograph (figure 1) showed a large left-sided pleural effusion and extensive pleural disease. A physical examination showed prominent veins on the left neck and overlying the anterior area of the left part of her chest. Breathing sounds were

\footnotetext{
I Department of Radiation Oncology, Massachusetts General Hospital, Harvard Medical School, Boston, Massachusetts, United States.
}

Reprint requests to: Dr M Huncharek, Department of Radiation Oncology, Massachusetts General Hospital, Harvard Medical school, Boston, Massachusetts 02114, USA. markedly diminished over the entire left hemithorax. The remainder of her examination was unremarkable. She reported no significant past medical history.

A thoracentesis was performed which was nondiagnostic. The results of a needle biopsy were suspicious for mesothelioma and on the second hospital day a bronchoscopy and thoracotomy were performed. No endobronchial tumor was noted although the left basilar segmental bronchus was occluded by extrinsic compression. A partial pleurectomy and decortication of the left lower lobe was carried out. Pathological examination showed malignant mesothelioma of the epithelial subtype with positive staining for cytokeratins. The tumor was carcinoembryonic antigen (CEA) and LUE-M1 negative. Examination by electron microscopy revealed large,

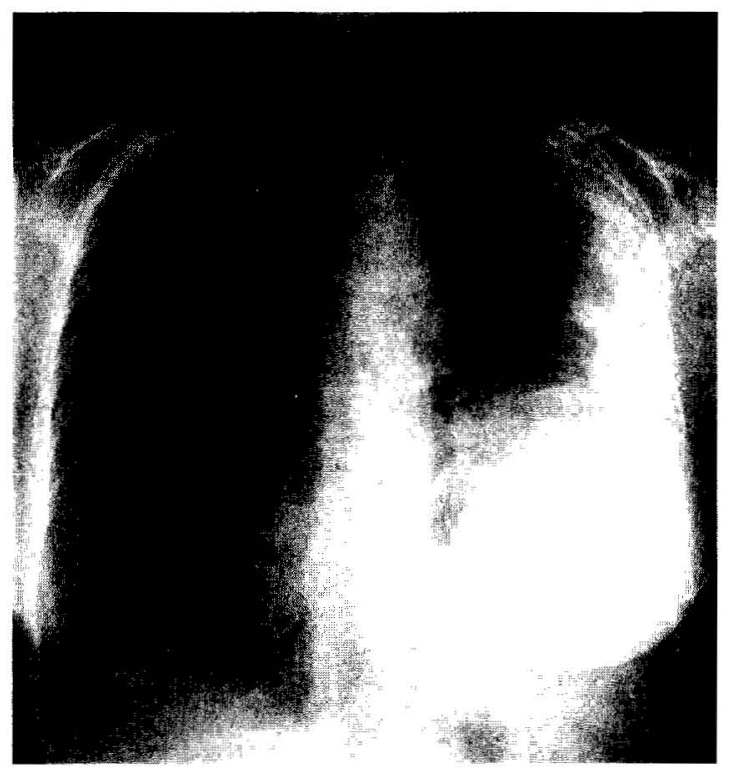

Figure 1. Chest radiograph showing pleural mass in the left hemithorax. 
oval neoplastic cells, focally raised into microvilli. Some of the cells had microfilaments and tonofibrils.

The patient had an uneventful postoperative course and was discharged in one week in good condition. She died at home two months after the surgery, prior to beginning chemotherapy.

A complete occupational history was obtained prior to her death. Upon graduation from high school in 1954 she was employed as a payroll clerk for a company which manufactured cigarette filters. The primary components of the filter were asbestos (crocidolite), cotton, and acetate fibers (6). During her senior year in high school, the patient had been employed by this company as a payroll clerk on a parttime basis. Although she had no direct contact with the cigarette filter manufacturing process, she made daily trips to the mill to pick up the workers' time sheets. She was also directly involved in distributing pay checks to the company's employees.

At the time of her marriage, she stopped working until 1970 . She then began work as a clerk in a municipal department and held a series of clerical jobs until her diagnosis of mesothelioma in 1989. No occupational exposures were noted during the period $1970-1989$.

The patient's husband had worked in the same cigarette filter company. He reported working for seven months in the filter manufacturing plant where acetate, cotton, and crocidolite asbestos were blended. The work conditions were described as extremely dusty. At the end of his workshift, he stated that he ". . . looked like a huge teddy bear ... Y You were covered with dust and the fibers of all three components, the acetate, the cotton and the asbestos." These descriptions were corroborated by air sampling conducted at several production locations in the factory on 27 October 1952 (6). As mentioned by Talcott et al, these measurements showed an airborne concentration of 80 particles of asbestos dust per milliliter of air. The patient's hustand had no other occupational exposure to asbestos and died of asbestosis in 1982.

\section{Discussion}

The incidence of pleural mesothelioma has risen over the last two decades. Data from the National Cancer Institute's program of population-based registries, called SEER (surveillance epidemiological and end results), show that the annual age-adjusted incidence for the years 1973 to 1978 versus 1979 to 1980 increased by almost $10 \%$ per year (among men) (1). More recent data from SEER shows that the incidence rate among white men for the period 1973 1984 increased from 0.7 per 100000 persons to 1.8 per 100000 persons (1).

The etiologic link between asbestos and mesothelioma is well known. Disease risk is no longer confined to workers in the asbestos industry. Occupational groups using various asbestos products, for example, insulators, pipe fitters, construction workers, brake mechanics, and railraod workers, have been shown to experience a high incidence of this tumor. In addition, household contacts of asbestos industry workers have been described as being at risk, and this phenomenon demonstrates that "secondary" or "bystander" exposure to asbestos may represent a serious health hazard (7).

In 1989, Talcott et al (6) reported on the occurrence of asbestos-associated diseases in a cohort of workers employed in the same factory as the patient in this case report. The 33 men described by Talcott and his co-workers were all involved in the manufacturing process itself with exposure to crocidolite asbestos. Industrial hygiene surveys conducted at the plant in the 1950 s revealed a very high airborne asbestos concentration (ie, 80 particles per milliliter of air). Overall mortality was increased in this group, 15 of 28 deaths being due to cancer as compared with the 8.3 expected. Eight died from lung cancer, five from mesothelioma, and two from other types of cancer.

The patient described in the present report had three potential sources of asbestos exposure, name$1 y$, (i) exposure during the workday via trips through the manufacturing plant to pick up payroll material, (ii) secondary exposure from contaminated workers entering the payroll office, which was her primary work area, and (iii) domestic exposure from her husband's workclothes. It is important to note that the patient's husband died from asbestosis secondary to heavy asbestos exposure at the same manufacturing plant.

This case report presents a case of pleural mesothelioma associated with unusual occupational and nonoccupational exposure to asbestos. Such exposures are often unrecognized and therefore have medical, legal, and public health implications. Physicians and public health professionals need to be aware of unusual sources of asbestos exposure in order to institute appropriate management and preventive measures.

\section{References}

1. Ries LAG, Hankey BF, Miller BA, et al. Cancer statistics review 1973-1988. Bethesda, MD: National Cancer Institute, 1991. (NIH pub no 91-2789.)

2. Churg A. Malignant mesothelioma in British Columbia in 1982. Cancer 1982;55:672-4.

3. Newhouse M. Epidemiology of asbestos related tumors. Semin Oncol 1981;8:250-7.

4. Huncharek M. The epidemioldogy of pleural mesothelioma: current concepts and controversies. Cancer Invest $1989 ; 7: 93-9$.

5. Huncharek M. Changing risk groups for malignant mesothelioma. Cancer 1992;69:2704-11.

6. Talcott JA, Thurber WA, Kantor AF, et al. Asbestos associated diseases in a cohort of cigarette filter workers. N Engl J Med 1989;321:1220-3.

7. Anderson HA, Lilis R, Daum SM, et al. Household contact asbestos neoplastic risk. Ann NY Acad Sci 1976;271:311-23.

Received for publication: 28 September 1993 